\title{
Metodología para el análisis de repositorio institucional de colecciones audiovisuales digitales
}

\author{
Jorge CALDERA SERRANO \\ jcalser@alcazaba.unex.es \\ Departamento de Información y Comunicación \\ Universidad de Extremadura
}

Recibido: $14 / 05 / 2013$

Aceptado: 25/05/2013

\section{RESUMEN}

Se presenta una herramienta de evaluación de los repositorios de colecciones audiovisuales digitales para determinar la calidad y validez del acceso, disponibilidad y visualización de los documentos audiovisuales contenidos en las mismas. Por lo tanto, esta herramienta es válida tanto como guía para la creación de nuevos repositorios como para la auditoría interna de los ya existentes. Para ello se han utilizado herramientas probadas con anterioridad tanto para la evaluación de Interfaz como información sobre visibilidad, políticas de acceso y autoría, interoperabilidad, etc., generando la herramienta propia de evaluación audiovisual partiendo de la bibliografía reseñada en la metodología.

Palabras clave: colecciones audiovisuales, repositorio audiovisual, Auditoría interna, guía de implantación, documentación audiovisual digital.

\section{Methodology for analyzing institutional repository digital audiovisual collections}

\begin{abstract}
We present an evaluation tool for repositories of digital audiovisual collections to determine the quality and validity of access, availability and display of audiovisual documents contained therein. Therefore, this tool is valid as a guide for creating new repositories as internal audit of existing ones. This has been used previously proven tools for the evaluation of interface as information on visibility, access policies and authorship, interoperability, etc... Generating the visual evaluation tool itself based on the literature reviewed in the methodology.

Keywords: Audio-visual Collections, Audio-visual Repository, Internal Audit , Implementation Guide, Digital Audio-visual Documentation.
\end{abstract}




\section{LAS COLECCIONES AUDIOVISUALES EN LA RED}

El material audiovisual impregna todas las facetas de la vida. Lo audiovisual y su transmisión por pantalla a marcado y está marcando a una nueva generación denominado por Marc Prensky "nativos digitales". Estos han crecido entre pantallas: la del ordenador, del videojuego, de la televisión y del teléfono celular. Han crecido disfrutando de lo audiovisual, educándose gracias a lo audiovisual, comunicándose en un entorno audiovisual.

El nacimiento, y muy especialmente, el desarrollo de la red ha generado también que el material audiovisual se haya convertido en protagonista de nuevas formas de lectura, de escritura, en definitiva, de comunicación.

La red potencia lo audiovisual, ya que lo audiovisual potencial la red, y es en esta red donde los medios audiovisuales y las colecciones en estos formatos han encontrado la mejor plataforma para poder presentar, exponer y difundir sus productos audiovisuales, ya sea mediáticos, educativos, de entretenimiento, o de otra cualquier índole.

Por lo tanto, el presente trabajo pretende analizar y marcar cuáles son las pautas que se estiman debieran ser las idóneas para el desarrollo, implantación, presencia y difusión de las colecciones audiovisuales en la red, en definitiva, cuáles son los elementos que debe contener y con las que debe contar una colección audiovisual en la red para que pueda ser considerada de máxima calidad.

No obstante, los elementos aquí planteados deberán ser valorados por cada empresa que vuelque sus contenidos audiovisuales en la red, estimando hasta que punto es útil o no cada uno de los parámetros señalados en este trabajo conforme a los objetivos y fines de la entidad.

Esta nueva formula de volcado de información en la red se está incrementando de manera exponencial en los últimos años, sobre todo en proyectos que contribuyen a la difusión de la información en acceso abierto (Open Access). Aunque no todas las colecciones audiovisuales son absolutamente abierta -sino que muchas de ellas son de pago para visualizar contenidos- la tendencia es el acceso abierto especialmente en ámbitos educativos, divulgativos y científicos.

Por lo tanto, el objetivo del presente trabajo es mostrar un método de evaluación de las colecciones audiovisuales en la red para valorar su calidad en la información y condiciones de publicación en la red. Además de un método de evaluación es, sin lugar a duda, un mecanismo y herramienta que puede ser tenida en cuenta por las empresas que vuelquen sus contenidos en la red como fórmula de llevar a cabo un proceso de auditoría interna y evaluación de su presencia en la red. 


\section{METODOLOGÍA Y PRINCIPALES FUENTES}

Como señalaremos posteriormente, utilizamos el trabajo realizado por el grupo RECOLECTA (2010) como base o pieza fundamental para nuestro trabajo. Por ello utilizamos su definición de repositorio institucional de investigación "Conjunto de servicios prestados por las universidades o centros de investigación a su comunidad para recopilar, gestionar, difundir y preservar su producción científica digital a través de una colección organizada, de acceso abierto e interoperable", siendo por tanto necesario para acabar de definir nuestro objeto de análisis identificar lo que entendemos por colecciones audiovisuales: conjunto de registros informáticos accesibles por la red en forma de imágenes en movimiento y/o sonido potencialmente con relación de forma sincronizada.

Además señala las siguientes variables del repositorio:

- Sus funciones son la de recopilar, gestionar, difundir y preservar la producción de la institución.

- Los documentos albergados deben estar presentes de forma acumulativa y perpetua.

- Los documentos del repositorio deben ser creados por la institución.

- La colección debe estar organizados y accesibles, no siendo un mero depósito de documentos. Para ellos deberá de contar con fórmulas de acceso válidas por medio de una descripción adecuada.

- Los repositorios deben ser de acceso abierto con el fin de aumentar la visibilidad e impacto del material audiovisual.

- Interoperabilidad del repositorio a través de la utilización de protocolos estandarizados.

\section{La metodología}

Para realizar esta herramienta hemos partido de tres documentos claves, los han cuales han influido uno en otros, y en definitiva, éstos han influido en la filosofía de la herramienta que presentamos $y$, evidentemente, parte de sus resultados han sido plasmado en la herramienta auditora.

\section{DINI (Deutsche Initiative für Netzwerkinformation E.V.)}

DINI (2006) se funda entre las universidades alemanas con el fin de mejorar los servicios de información y comunicación, desarrollando las infraestruturas tecnológicas informativas que son necesarias para la creación de estos productos.

Desarrolla un "certificado" expedido por DINI a los diferentes repositorios que cuenten con unos criterios mínimos que se estiman básicos para la difusión de los resultados de la investigación científica de las universidades alemanas. En definitiva, centra su análisis en el fin último de la difusión y visualización de los contenidos 
puestos en el repositorio por la institución académica, tanto a nivel nacional como internacional.

DINI cuenta con grupos de trabajo que, de forma constante, evoluciona sus herramientas atendiendo a los cambiantes criterios nacionales e internacionales. Los datos evaluados pertenecen a los siguientes ítems: visibilidad, políticas, asesoramiento a autores, aspectos legales, seguridad e integridad, accesibilidad y disponibilidad a largo plazo de la información.

\section{DRIVER (Digital Repository Infraestructure Vision for European Research)}

Otra iniciativa interesante, en este caso con visión europea, es DRIVER (2008), la cual cuenta como misión el recolectar los contenidos digitales de los repositorios abiertos de investigación de ámbito europeo, contando así con la posibilidad de generar herramientas de recuperación y consulta sobre todos estos repositorios siempre y cuando cuente con estructuras similares y protocolos de comunicación comunes.

Las directrices DRIVER, al igual que DINI, señala los requerimientos que debieran cumplir los repositorios, así como servir de guía para todos aquellos nuevos repositorios que quieran estar en el marco de DRIVER. Igualmente es para información académica científica. DRIVER considerará como válido a los repositorios que cumplen una serie de puntos obligatorios, mientras que los identificará con futuro si cumplen los puntos recomendados.

DRIVER parte del trabajo realizado por países que han llevado a cabo experiencias previas como son HAL (Francia), DARE (Países Bajos), Certificado DINI (Alemania) y/o SHERPA (Reino Unido).

\section{RECOLECTA}

RECOLECTA (2010) resumen su "Guía para la evaluación de repositorios institucionales de investigación" señalando su objetivo general elaborar unas directrices que sirvan de guía para los creados de repositorios para que les permita realizar una evaluación.

Esta herramienta, al igual que la anterior, desea ser una herramienta de audotoría interna para los repositorios institucionales, siendo una herramienta creada a partir de las anteriores experiencias y adaptadas a la realidad de España.

La guía de evaluación cuenta en su web http://www.recolecta.net/wiki/ index.php?title $=$ GTERIObjetivo 2 con cinco apartados: situación de los repositorios y su evolución en España; en segundo lugar aporta la metodología y así como el análisis de otras directrices; posteriormente ofrece el cuestionario; en cuarto lugar un glosario y en quinto y último una breve recopilación bibliográfica.

\section{Caldera y Nuño}

En último lugar, identificamos la monografía elaborada por Caldera y Nuño en 2004 donde identifica 80 puntos de acceso y tratamiento para la gestión de material 
audiovisual. Tomamos como base estos 80 puntos que son sin lugar a dudas metadatos que deben ser tenidos en cuenta para la recuperación de información en un ambiente de información audiovisual.

Los autores presentan la información por bloques informativos, relacionados con información de control, información onomástica, cronológica, temática, geográfica, datos de producción y emisión, entre otras cuestiones.

\section{HERRAMIENTA PARA LA AUDITORÍA DE COLECCIONES AUDIOVISUALES EN REPOSITORIOS INSTITUCIONALES}

Tal y como hemos señalado, la herramienta creada por RECOLECTA la estimamos como básica para ciertos elementos de control del repositorio de manera genérica, sin entrar a valorar cuestiones relacionadas con los contenidos y metadatos audiovisuales, por lo que la tomamos como un punto válido de partida.

La contestación a cada una de los elementos planteadas, y con el fin de simplificar el uso de la herramienta, contará con la posibilidad de contestar positiva o negativamente atendiendo a si se cumple el requisito mostrado por la pregunta.

\begin{tabular}{|l|}
\hline \multicolumn{1}{|c|}{ RECOLECTA } \\
\hline 1. VISIBILIDAD \\
\hline 1.1.- Mención del repositorio en la página principal de la institución \\
\hline 1.2.- Presencia en directorios nacionales e internacionales \\
\hline 1.3.- Presencia en recolectores nacionales e internacionales \\
\hline 1.4.- Existencia de un nombre normalizado en todos ellos \\
\hline 1.5.- Existencia de una URL amigable \\
\hline $\begin{array}{l}\text { 1.6.- Existencia de iniciativas para fomentar la visibilidad del repositorio dentro de la propia } \\
\text { institución }\end{array}$ \\
\hline $\begin{array}{l}\text { 1.7.- Al menos el 75\% de los recursos audiovisuales que ofrece el repositorio se encuentran en } \\
\text { acceso abierto }\end{array}$ \\
\hline 2.-POL/TICAS \\
\hline 2.1.- Existe una declaración sobre la misión y objetivos del repositorio \\
\hline $\begin{array}{l}\text { 2.2.- Política pública sobre el archivo en el repositorio, donde se establecen al menos los } \\
\text { siguientes puntos: quién puede depositar, qué se puede depositar y en qué formatos }\end{array}$ \\
\hline 2.3.- Politica pública sobre preservación de los contenidos \\
\hline 2.4.- Politica pública sobre reutilización de metadatos \\
\hline 2.5.- Existe una oferta de contacto y asesoramiento visible \\
\hline
\end{tabular}




\begin{tabular}{|c|}
\hline 3.- ASPECTOS LEGALES \\
\hline $\begin{array}{l}\text { 3.1.- El autor debe reconocer que al depositar no está infringiendo ningún derecho de propiedad } \\
\text { intelectual }\end{array}$ \\
\hline $\begin{array}{l}\text { 3.2.- Existe una autorización por el autor o el titular de los derechos que permite la distribución de } \\
\text { contenidos }\end{array}$ \\
\hline $\begin{array}{l}\text { 3.3.- Existe documentación disponible en el repositorio que ayude al autor a decidir si puede o no } \\
\text { archivar el documento }\end{array}$ \\
\hline $\begin{array}{l}\text { 3.4.- Inclusión de la información sobre los derechos de autor en los metadatos exportados por el } \\
\text { repositorio }\end{array}$ \\
\hline 4.- METADATOS \\
\hline $\begin{array}{l}\text { 4.1.- Existe una política de indización conocida por los autores donde se establezca: lengua, } \\
\text { lenguajes utilizados, etc }\end{array}$ \\
\hline 4.2.- Se aplica algún sistema de clasificación normalizado \\
\hline $\begin{array}{l}\text { 4.3.- Se permite la exportación de metadatos en algún otro formato aparte del Dublin Core } \\
\text { Simple }\end{array}$ \\
\hline 4.4.- Se utiliza algún formato de metadatos técnicos y/o de conservación \\
\hline 5.- INTEROPERABILIDAD \\
\hline 5.1.- Se proveen los datos a través del protocolo OAl-PMH \\
\hline 5.2.- Se identifican los recursos que están en abierto a través de un set denominado DRIVER \\
\hline 5.3.- Se marcan los registros eliminados \\
\hline 5.4.- El tiempo de vida del testigo de reanudación es de un mínimo de veinticuatro horas \\
\hline $\begin{array}{l}\text { 5.5.- El correo electrónico del administrador del repositorio está disponible en la etiqueta } \\
\text { AdminEmail dentro de la respuesta a una orden Identify }\end{array}$ \\
\hline 5.6.- Existe una declaración de Description en la respuesta a una orden Identify \\
\hline 5.7.- Se usa el vocabulario de DRIVER en el campo dc:type \\
\hline 6.- LOGS YESTADISTICAS \\
\hline 6.1. - Los logs del servidor web donde está alojado el repositorio se archivan de forma indefinida \\
\hline $\begin{array}{l}\text { 6.2. El repositorio proporciona un servicio de estadisticas sobre el uso de los documentos } \\
\text { almacenados }\end{array}$ \\
\hline 7.- SEGURIDAD, AUTENTICIDAD E INTEGRIDAD DE DATOS. \\
\hline $\begin{array}{l}\text { 7.1.- Existe un procedimiento establecido sobre la elaboración de copias de seguridad, tanto del } \\
\text { software sobre el que funciona el repositorio, los metadatos y los documentos propiamente } \\
\text { dichos }\end{array}$ \\
\hline $\begin{array}{l}\text { 7.2.- Utiliza el repositorio identificadores persistentes para sus contenidos (DOIs, Handles, URNs, } \\
\text { etc.) }\end{array}$ \\
\hline
\end{tabular}

\section{Interfaz de consulta}

Un elemento clave para el acceso a los contenidos de los repositorios de cualquier tipo, y por supuesto también de las colecciones audiovisuales, es contar con una interfaz clara, amigable y eficaz por medio de la cual los usuarios puedan interoperar con el repositorio y recuperar la información. 
Por ello, el Interfaz deberá adaptase a los requerimientos del grupo poblacional que potencialmente serán los usuarios del repositorio, siendo necesario que exista un equilibrio entre la facilidad del uso y formas avanzadas de recuperación de información.

Partiendo de la revisión bibliográfica realizada por Sulé, Estivill y Gascón (2011) sobre los principales trabajos realizados en materia de evaluación y análisis de interfaz en bibliotecas digitales se han llegado a las siguientes consultas y elementos analizados. No obstante hemos de señalar que algunos de los aspectos serán propios del material audiovisual (todos incluidos en el epígrafe Audiovisual) mientras que el trabajo original analizado se basa en la recuperación de trabajos textuales.

\begin{tabular}{|c|}
\hline INTERFAZ DE CONSULTA \\
\hline 8. GENERALES DE INTERFAZ \\
\hline 8.1. ¿ Existen ayudas para la realización de las búsquedas? \\
\hline 8.2.- ¿Se pueden realizar búsquedas avanzadas? \\
\hline 8.3. ¿Cuenta con la opción de realizar la consulta en diferentes idiomas? \\
\hline 8.4.- ¿Existen diferentes modalidades de búsqueda y tipos de lenguajes de interrogación? \\
\hline 8.5. ¿Existe algún mecanismo para la corrección de errores durante la búsqueda? \\
\hline $\begin{array}{l}\text { 8.6. - ¿El sistema cuenta con la capacidad de presentar sugerencias sobre consultas similares o } \\
\text { con más resultados al usuario? }\end{array}$ \\
\hline 8.7.- ¿Existen indices que ayuden a las consultas? \\
\hline 8.8. ¿Cuenta con la capacidad de refinar los resultados obtenidos en las búsquedas? \\
\hline 8.9. ¿Facilita la posibilidad de visualizar el tesauro, listas de materias o control de autoridad? \\
\hline 8.10.- ¿Pueden aplicarse filtros para visualizar en un orden determinado los resultados? \\
\hline 8.11.- ¿Se cuenta con un servicio de difusión selectiva de información? \\
\hline 9. AUDIOVISUALES (Interfaz recuperación) \\
\hline 9.1. ¿Facilita la opción de decidir el método de bajada del archivo? \\
\hline 9.2.- En la presentación de resultados, ¿facilita un keyframes visual que identifica el contenido? \\
\hline $\begin{array}{l}\text { 9.3.- ¿Puede visualizarse el clip de video en baja resolución antes de bajarlo y considerar su } \\
\text { validez? }\end{array}$ \\
\hline 9.4. ¿El usuario puede bajar el archivo audiovisual a su archivo? \\
\hline $\begin{array}{l}\text { 9.5.- ¿Existe algún control para determinar la identificación de la persona que baja la } \\
\text { información? }\end{array}$ \\
\hline 9.6. ¿Facilita los metadatos descriptivos del documento además del propio material? \\
\hline 9.7.- ¿Cuenta con contadores de descarga de cada uno de los documentos? \\
\hline
\end{tabular}

\section{Puntos de acceso al contenido audiovisual}

Independientemente de contar con buenas herramientas de control y acceso a la información, es fundamental que el material audiovisual cuente con puntos de acceso asociados a las imágenes (metadatos) que otorguen la posibilidad de recuperar la información por diferentes elementos.

El material audiovisual es sin lugar a dudas complejo, donde es necesario el 
análisis de la banda imagen y de la banda sonido, que no siempre tienen una relación sincrónica. Además, la unión de ambas bandas dan como resultado un nuevo producto y un nuevo mensaje que debe ser tratado de forma detallada.

Igualmente hemos de reseñar que existen muchos tipos de materiales audiovisuales, y cada uno de estos tipos tiene unas características, funciones, fines y objetivos diferentes. No es lo mismo un material audiovisual propio de una cadena de televisión que el material audiovisual docente recogido en un repositorio audiovisual de una universidad. De ahí lo complejo y la necesidad de plasmar diferentes elementos para que, dependiendo del tipo de colección, deba definirse cuáles son los elementos necesarios a plantear en el repositorio, siempre atendiendo a la realidad de los usuarios del mismo.

\begin{tabular}{|c|}
\hline PUNTOS DE ACCESO AL CONTENIDO AUDIOVISUAL \\
\hline 10.- PUNTOS DE ACCESO POR ELEMENTOS FORMALES \\
\hline 10.1. ¿Se identifican los aspectos formales del vídeo más reseñables? \\
\hline 10.2. ¿Se señala la calidad de la comprensión del vídeo? \\
\hline 10.3. ¿Se determina cuál se el método para la visualización correcta del vídeo? \\
\hline 10.4.- ¿Se aclara la duración del vídeo? \\
\hline 10.5. ¿Se aclara si las imágenes tienen Insertos y elementos de postprodución? \\
\hline 10.6.- ¿Se aclara si el material es bruto, montado o semi-montado? \\
\hline $\begin{array}{l}\text { 11:- PUNTOS DE ACCESO POR ELEMENTOS DE CONTENIDO. DESCRIPCION DE } \\
\text { IMAGENES }\end{array}$ \\
\hline 11.1. ¿Se le facilita un titulo al vídeo? \\
\hline 11.2.- En caso de tener título, ¿cuenta con alguna normativa de elaboración? \\
\hline 11.3. ¿Se realiza un resumen del contenido visual y/o sonoro del documento? \\
\hline 11.4. - En caso de realizarse el resumen, ¿cuenta con alguna normativa de elaboración? \\
\hline 11.5.- ¿Se lleva a cabo una descripción de imágenes y/o secuencias? \\
\hline $\begin{array}{l}\text { 11.6. - En caso de contestar positivamente a la cuestión } 11.5 \text { conteste: ¿Se identifican los } \\
\text { planos? }\end{array}$ \\
\hline $\begin{array}{l}\text { 11.7.- En caso de contestar positivamente a la cuestión } 11.5 \text { conteste: ¿y los movimientos de } \\
\text { cámara? }\end{array}$ \\
\hline 11.8.- En caso de contestar positivamente a la cuestión 11.5 conteste: $2 y$ los efectos visuales? \\
\hline $\begin{array}{l}\text { 11.9. - En caso de contestar positivamente a la cuestión } 11.5 \text { conteste: ¿se identifican la time } \\
\text { code en cada una de las descripciones de forma clara? }\end{array}$ \\
\hline 11.10.- Y si existe material trucado, ¿se señala? \\
\hline 11.11. ¿se señala si la imagen es profesional, semiprofesional o amateur? \\
\hline 11.12. ¿se realiza alguna normativa a la descripción de imágenes? \\
\hline 11.13.- Ponga algunos ejemplos de descripción de imagen \\
\hline 12.- PUNTOS DE ACCESO POR ELEMENTOS DE CONTENIDO. DESCRIPCION TEMATICA \\
\hline 12.1.- ¿Se realiza descripción temática? \\
\hline $\begin{array}{l}\text { 12.2. En caso de realizarse, ¿se distingue entre temas visualizados por la banda imagen de la } \\
\text { aportada por la banda sonora? }\end{array}$ \\
\hline 12.3.- ¿se incluye todo dentro de un único campo? \\
\hline 12.4. ¿Cuentan con herramientas documentales de control temático? \\
\hline 12.5. - Ponga algủn ejemplo \\
\hline
\end{tabular}




\begin{tabular}{|c|}
\hline $\begin{array}{l}\text { 13.- PUNTOS DE ACCESO POR ELEMENTOS DE CONTENIDO. DESCRIPCION } \\
\text { ONOMASTICA }\end{array}$ \\
\hline 13.1.- ¿Se realiza descripción onomástica? \\
\hline $\begin{array}{l}\text { 13.2.- En caso de realizarse, ¿se distinguen entre personas visualizadas por la banda imagen de } \\
\text { la aportada por la banda sonora? }\end{array}$ \\
\hline 13.3.- ¿se incluye dentro de un único campo? \\
\hline 13.4.- ¿distinguen entre las personas fisicas de las personas juridicas en campos especificos? \\
\hline 13.5. ¿Cuentan con herramientas de control de autoridad? \\
\hline 13.6.- En caso negativo, ¿Cómo controlan los puntos de acceso onomásticos? \\
\hline $\begin{array}{l}\text { 14.- PUNTOS DE ACCESO POR ELEMENTOS DE CONTENIDO. DESCRIPCIÖN } \\
\text { GEOGRAFICA }\end{array}$ \\
\hline 14.1.- ¿Se realiza descripción geográfica? \\
\hline $\begin{array}{l}\text { 14.2.- En caso positivo, ¿identifican país, estado, ciudad o localización exacta donde se captan } \\
\text { las imágenes? }\end{array}$ \\
\hline 14.3.- ¿Se identifican elementos que potencialmente sean visualizados en las imágenes? \\
\hline 14.4.- ¿Cuentan con herramientas documentales para el control de lugares? \\
\hline 14.5.-En caso negativo, ¿Cómo controlan los puntos de acceso geográficos? \\
\hline $\begin{array}{l}\text { 15.- PUNTOS DE ACCESO POR ELEMENTOS DE CONTENIDO. DESCRIPCION } \\
\text { CRONOLOGICA }\end{array}$ \\
\hline 15.1. ¿ ¿Se realiza descripción cronológica? \\
\hline 15.2.- En caso positivo, ¿identifican las fechas de captación de las imágenes? \\
\hline 15.3. - En caso de que sea relevante, ¿se señala fecha de emisión, producción o reemisión? \\
\hline $\begin{array}{l}\text { 16.- PUNTOS DE ACCESO POR ELEMENTOS DE PRODUCCION, DISTRIBUCION Y } \\
\text { AUDITORIA. }\end{array}$ \\
\hline 16.1.- ¿Se identifica el responsable físico o institucional de la producción? \\
\hline 16.2. ¿Se identifica el responsable físico o institucional de la distribución? \\
\hline 16.3. ¿Señala claramente la autoría de las imágenes? \\
\hline $\begin{array}{l}\text { 16.4- ¿Se identifican las posibles restricciones de acceso y uso de las imágenes? (e } \\
\text { que las hubiera) }\end{array}$ \\
\hline
\end{tabular}

\section{Calidad física del contenido audiovisual}

Un elemento fundamental que debe también analizarse es si el material que se observa en la colección cuenta con la calidad suficiente para ser difundidos por un repositorio de calidad. La producción del material audiovisual requiere de unos medios de captación de audio y vídeo más o menos exigentes para que pueda entenderse de forma correcta. Y la realidad nos muestra que en muchas ocasiones sí que existe una alta profesionalización en la captación de las imágenes, no obstante existen problemas en la captación de sonidos al requerir equipos externos micrófonos- para la captación correcta.

Por ello, para evaluar la calidad de este material, deberá analizarse los aspectos de visualización y audición del material. 


\begin{tabular}{|l|}
\hline \multicolumn{1}{|c|}{ CALIDAD FISICA DEL CONTENIDO AUDIOVISUAL } \\
\hline 17. CALIDAD FISICA DEL MATERIAL \\
\hline $\begin{array}{l}\text { 17.1.- Tras una cata representativa sobre la colección, ¿el audio del material cuenta con calidad } \\
\text { de audición? }\end{array}$ \\
\hline $\begin{array}{l}\text { 17.2.- Tras una cata representativa sobre la colección, ¿el vídeo del material cuenta con calidad } \\
\text { de visualización? }\end{array}$ \\
\hline
\end{tabular}

\section{CONCLUSIONES}

Lo desarrollado en este trabajo es una herramienta auditora para aquellas empresas que cuentan con colecciones audiovisuales disponibles por medio de la red, y especialmente, para aquellas que cuentan con acceso abierto. Sirve por tanto para valorar hasta qué punto se están exponiendo los contenidos de forma correcta y unos criterios de calidad que garantizan que los contenidos cuentan con una facilidad de accesibilidad y también de integridad documental.

Además de ser una herramienta auditora, puede servir de guía a aquellas empresas que desean poner a disposición de un amplio colectivo su colección audiovisual, teniendo por tanto una herramienta que da pautas para mejorar la difusión de estos contenidos.

Son cada vez más las instituciones que deciden poner en acceso abierto su información científico, técnica, cultural y/o social, derivado de que es una forma fácil, sencilla y también barata de poner a disposición de todos dichos contenidos, siendo por tanto más utilizados y más citados. Son cada vez más y más, y serán estas variantes de control de calidad las que puedan hacer girar la balanza hacia el uso de unos repositorios u otros.

\section{RECONOCIMIENTOS}

Este trabajo ha sido financiado por la Junta de Extremadura (Consejería de Educación, Ciencia y Tecnología) y el Fondo Social Europeo dentro del plan de apoyo a las actuaciones de los Grupos de Investigación inscritos en el catálogo de la Junta de Extremadura. GR10019. 


\section{BIBLIOGRAFÍA}

CALDERA SERRANO, J; Nuño Moral, MV (2004). Diseño de una base de datos para televisión. Gijón, Trea.

Deutsche Initiative für Netzwerkinformation. DINI-Certificate Document and Publication Services. [en línea] 2007. [Version 2.0, September 2006] [Consulta 01/02/2013] http://nbn-resolving.de/urn:nbn:de:kobv:11-10075687

DRIVER Project. Directrices DRIVER 2.0. Directrices para proveedores de contenido - Exposición de recursos textuales con el protocolo OAI-PMH. [en línea] (2008) [Traducció de Rebiun] [Consulta 01/020/2013] http://www.driver-support.eu/documents/DRIVER_2_1_Guidelines_Spanish.pdf

Recolecta: recolector de ciencia abierta. [Consulta 01/02/2013] http://www.recolecta.net/buscador/index.jsp

SULÉ DUESA, A.; ESTIVILL RIUS, A. Y GASCÓN GARCÍA, J. Evaluación de las interfaces de consulta de las colecciones digitales patrimoniales españolas. Anales de Documentación, 2011, vol. 14, no 2. Disponible en: $<$ http://revistas.um.es/analesdoc/article/view/113931> [Consulta 01/02/2013] 